\title{
MULTIPLE BREAKPOINT TEST ON CRUDE OIL PRICE
}

\author{
Seuk Wai PHOONG*, Seuk Yen PHOONG**, Sedigheh MOGHAVVEMI***, Kok Hau PHOONG**** \\ *, ***University of Malaya, Faculty of Business and Accountancy, Kuala Lumpur, MALAYSIA \\ *e-mail: phoongsw@um.edu.my \\ ***e-mail: sedigheh@um.edu.my \\ **Sultan Idris Educational University, Faculty of Science and Mathematics, Perak, MALAYSIA \\ e-mail: phoong@fsmt.upsi.edu.my \\ ****Sultan Azlan Shah University, Faculty of Management and Information Technology, \\ Perak, MALAYSIA \\ e-mail: pkh66885669@hotmail.com
}

\begin{abstract}
The impact of structural changes as well as breaks on oil price fluctuations is studied in this article. There are a few channels, such as domestic prices and inflation, that cause the effect of oil price to pass through the economy. The higher crude oil price is immediately followed by the increase in oil products such as gasoline and heating oil. The direct effects continue as people choose alternative energy sources, leading to the increase in price. Besides, the indirect effect on inflation as a result of the behavioral responses of the firms and workers which is known as the "second round" effects in which higher wages is being demanded. This article uses exploratory data analysis to discover the patterns of the variables' series and then examines the relationship between oil price and consumer price index. Multiple breakpoint test is thereafter used to identify the structural changes in time-varying variables.
\end{abstract}

Keywords: breakpoint test, consumer price index, oil price, exploratory data analysis.

JEL: C580, E320.

\section{$1 \quad$ Introduction $^{1}$}

According to the Energy Intelligence Group, there are approximately 200 varieties of crude oil with different grades found under the surface of the earth. Crude oil is of little function before being refined and is highly traded for its final petroleum products. The viscosity and sulfur content are the two most significant qualities of crude oil. The light crude, known with its lower density, produces more valuable final products, such as gasoline and other light petroleum products, through a simple refining process named as distillation. In contrast, heavy crude oils have a lower share of light hydrocarbon and have to undergo more severe refining processes, such as cooking and cracking, in order to produce similar proportions of more valuable petroleum products.

\footnotetext{
${ }^{1}$ This article was submitted at the Asian Business and Economics International Conference 2019 (ABEIC 2019), Kangwon National University (KNU), Chuncheon, South Korea, April 25 27, 2019 (https://submit.confbay.com/conf/abeic2019).
}

The American Petroleum Institute (API) gravity is used to measure the densities of petroleum liquids. In addition, the sulfur element is an unwanted property that the refiners have to invest highly in order to remove it. Crude oils with low sulfur content are known as sweet crudes, while crude oils with high content of sulfur are referred to sour crudes. Different types of crude oil are priced differently as the type of crude oil has a bearing on refining yields. The light crude, which is also known as sweet crude, is sold at a premium over the heavy or sour crude due to the higher proportion of more valuable final petroleum products yielded.

The benchmark crude oil serves as a pricing reference to the sellers and buyers. Crude oil is the most important commodity in the world. Many oil products and its derivatives are used in the modern life, ranging from transportation to plastics. There is a general misconception among the investors about the types of oil prices and how they affect the global trading. Although there are several countries that produce oil, but crude oil is an oligopoly market and classified into three benchmarks price, West 
Texas Intermediate (WTI), Brent Blend (Brent), and Dubai Crude. The United States used WTI as a benchmark in trading the oil. However, some of the countries outside the United States priced off the Brent. However, Dubai crude oil price is the benchmark for the oil exported from the Middle East to the Asia countries.

The changes in oil price are treated as one of the factors affecting the level of economic activities at the global and national levels. For instance, almost all the recession in the United States is affected by the increase in oil prices. The manner in which oil prices affect emerging and developing economies has received surprisingly attention compared to advanced economies. Hamilton and Lin (1996), Chaudhuri and Daniel (1998), Sauter and Awerbuch (2003), and Phoong, et al. (2018) discussed the effect of oil prices to the role of monetary policy, costs or firms, labor market, exchange rate, stock market, and the intensity of oil in production.

The rapid and largely unexpected collapse in oil price for the past few years sparked a debate on the effect of oil price shock on inflation (Phoong and Phoong, 2017). Oil price is commonly linked with the inflation in a correlation relationship or a causal relationship. Inflation is accomplished by dividing a monetary time series by a price index, such as Consumer Price Index (CPI). CPI is seen as a general indicator of the change in retail price paid to households for goods and services. It is used to measure the rates of price inflation as experienced and perceived by households in their role as consumers. Moreover, it is also a proxy of inflation for the economy and the key statistics for the purpose of economic policy making, especially monetary policy. CPI can provide an approximation to a costof-living index that measures the changes in the general level of prices of a fixed basket of goods and services that represent the items that are normally consumed by an average household in a country with reference to the base period (Yuan and $\mathrm{Li}$, 2010).

CPI is calculated based on the price of about 430 representative items such as food and beverages, tobacco, clothing and footwear, transport, and communication selected based on the household expenditure survey. The usefulness of CPI allows consumers to determine the changes in price on their purchasing power, as a yardstick for revising wages, pensions, alimony and payments, and as an indicator of the rate of inflation in the country.

The relationship between inflation and economic growth has been a long debate topic in the field of economics. For the structuralisms, inflation is crucial for economic growth, whereas from the monetarists point of view, inflation is detrimental to the growth of economy, as mentioned by Mallik and Chowdhury (2001). There are various studies that have been conducted to investigate the inflationary consequence of oil price changes and there are two focuses: macro-oriented focus and micro-oriented focus. The macro-oriented literatures studied the effect of oil prices on goods prices at aggregate level, whereas micro-oriented studies examined the consequence at the commodity level (Carruth, et al., 1998; Davis and Haltiwanger, 1999; Cong, et al., 2008; Ibrahim and Chancharoenchai, 2014).

As inflation is one of the macroeconomic variables, its asymmetric relationship with oil prices has also been proven in many past studies. The failure of the oil price collapse in 1986 leading to a growth in economy showed the existence of asymmetric relationship between the oil price and macroeconomic activities. The negative effects can be observed on the rising of oil price. However, the depreciation of oil price may not cause a positive impact, but instead, slow down the output growth. In fact, Hooker (2002) also emphasized that the linear, constant-coefficient specifications in most Phillips curve may not be able to capture the relationship between oil price and inflation.

Cunado and De Gracia (2005) made a major contribution by using different oil output and oil CPI specification to examine the impact of oil prices on economic growth and inflation in six Asian countries such as Japan, Singapore, South Korea, Malaysia, Thailand, and Philippines using quarterly data from 1975 to 2002 . The results showed that there is an asymmetric relationship between the oil price and inflation rate in Japan, Thailand, South Korea, and Malaysia. The finding, however, contrast with the study conducted by Hooker (2002). The impact of change in oil price on the U.S. inflation was evaluated in the framework of Phillips curve using An- 
drew's test, while allowing for asymmetries, nonlinearities, and structural breaks, as stated in the past literature on the real effects of oil price shocks (Hooker, 2002). It is found that the structural break specification gives a better fit to the data as compared to the asymmetric and nonlinear specifications that have produced relatively poor fit. According to Ibrahim and Chancharoenchai (2014), oil price is inflationary for general price level and the adjustment process of consumer price is noted to be asymmetry. The consumer price tends to rise faster with the increase in oil price. However, when there is a decline in oil price, immediate offsetting effect is not observed and the consumer price remains high.

In this article, we model the relationship between oil price and CPI and then study whether these correlations are significant. Besides, we also estimated the structural change as well as the breaks of the crude oil price using multiple breakpoint tests and verified the breaks by relating with the economic events and monetary policy.

\section{Methodology}

This article has two main objectives. The first objective is to measure the relationship between oil price and CPI. By studying the correlation, we will be able to observe the relationship between the oil price and CPI. The second objective is to investigate the structural change as well as breaks for the WTI crude oil price. By studying the breaks, we will be able to investigate the events that contribute to the structural changes in the time series.

\subsection{Data and sample size}

To examine the structural changes as well as breaks of the oil price and CPI, monthly data covering the period from January 1980 to April 2016 are used. The data were collected from the U.S. Department of Energy and Bureau of Labor Statistics.

The benchmark crude oil price used in this article is WTI crude oil price with the conversion method of average. Moreover, the WTI oil price is measured in U.S. dollars per barrel. There is no seasonal adjustment to the data and the data are a current average crude oil price. The CPI data adopted in this article are probably the best known U.S. price index, compared to other price index, such as Producer Price Index and Gross Domestic Product Implicit Price Deflator in representation of the country inflation. The CPI is measured inflation as experienced by consumers in their day-to-day living expenses.

\subsection{Research Methodology}

An exploratory data analysis (EDA) is used to analyze and summarize the data sets. EDA is an approach that uses variety of techniques, including graphical techniques, such as scatter plots, bar, box plot, and histogram; and quantitative techniques, such as descriptive statistics in understanding and measuring the properties of the data (Behrens and $\mathrm{Yu}, 2003)$. In this study, EDA is adopted to identify the patterns of the time series because this approach is able to measure the data from many different angles; transform the data through some nonlinear operator, projecting the data onto different subspace; and subsequently examine the resulting distribution.

Time series involves decomposing the time series into trend, cyclical, and seasonality components. Stochastic processes are one of the types of time series models. Most of the physical process in the real work has a random element in their structure and a stochastic process can be described as a statistical phenomenon that evolves in time according to probabilistic laws. Statistically, in order to model the uncertainty, it is assumed that for each time point $\mathrm{t}$ (monthly), $\mathrm{Y}_{\mathrm{t}}$ is a random variable. However, the sequence of random variable $\left(Y_{1}, Y_{2}, Y_{3}, \ldots\right)$ is called a stochastic process. As the process is random, and we are trying to model it, there must be some characteristics that have to remain stable over the time. This characteristic is the main feature of a stationary time series. Therefore, unit root test is used to determine the stationarity of the variables.

Multiple breakpoint test is used in this article to identify the breaks on oil price. If the oil price (including lag) changes gradually or abruptly over the time, then the "break" is said to exist in the series. Quandt (1960) modified the Chow (1960) breakpoint test and suggested the Quandt likelihood ratio (QLR) test. QLR statistic is superior in examin- 
ing the unknown break date and measuring the Chow breakpoint test at every observation by excluding the first and last $15 \%$ of the sample.

The Chow breakpoint test statistic is

$$
\lambda=\left(\mathrm{T}_{1}+\mathrm{T}_{2}\right) \log \widehat{\sigma}^{2}-\mathrm{T}_{1} \log {\widehat{\sigma}_{1}}^{2}-\mathrm{T}_{2} \log {\widehat{\sigma}_{2}}^{2}(1)
$$

where:

$\mathrm{T}$ - represents the full sample, $\mathrm{T}_{1}<\mathrm{T}_{\mathrm{B}}$ and $\mathrm{T}_{2} \leq \mathrm{T}-$ $T_{B}$ (before $T_{B}$ and after $T_{B}$ ), where $T_{B}$ is the break period;

$\widehat{\sigma}_{1}=\mathrm{T}_{1}^{-1} \sum_{\mathrm{t}=1}^{\mathrm{T}_{1}}\left(\hat{\mathrm{u}}_{\mathrm{t}}^{(1)}\right)^{2}$ and

$\widehat{\sigma}_{2}=\mathrm{T}_{2}^{-1} \sum_{\mathrm{t}=\mathrm{T}-\mathrm{T}_{2}+1}^{\mathrm{T}}\left(\hat{\mathrm{u}}_{\mathrm{t}}^{(2)}\right)^{2}$ where $\hat{\mathrm{u}}_{\mathrm{t}}$ represents the residuals.

The breakpoint F-test is

$$
F=\frac{\left[\widetilde{u}^{\prime} \widetilde{u}-\left(u_{1}{ }^{\prime} u_{1}+u_{2}{ }^{\prime} u_{2}\right)\right] / k}{\left(u_{1}^{\prime} u_{1}+u_{2}{ }^{\prime} u_{2}\right) /(T-2 k)}
$$

where $\tilde{u}^{\prime} \tilde{\mathrm{u}}$ represents the restricted sum of squared residuals, $u_{j}^{\prime} u_{j}$ is the sum of squared residuals from subsample $\mathrm{j}, \mathrm{k}$ is the number of parameters in the equation, and $\mathrm{T}$ represents the total number of observations.
The purpose of trimming the first $15 \%$ and last $15 \%$ of the sampling data and then estimated the series using Hansen's method is to make sure the subsample is not too near to the endpoint of the sample. Andrew (1993) and Andrew and Ploberger (1996) reviewed the QLR test and derived the limiting distribution of Quandt (1960) study. The present study will detect the existence of breakpoint in the time series data using Quandt-Andrew test. The null hypothesis of Quandt-Andrew test is no breakpoint within $15 \%$ trimmed data. After examining the presence of breaks in the data, Bai-Perron (2003) test is used to disclose the unknown break date.

\section{Results and discussion}

The exploratory data analysis of the variables includes descriptive statistics and line graph are showed to gather the basic features and virtually every quantitative analysis of the data.

Table 1. Descriptive statistics of the variables

(Source: Authors' own research)

\begin{tabular}{|l|c|c|}
\hline & $\begin{array}{c}\text { WTI } \\
\text { (WTI oil price) }\end{array}$ & $\begin{array}{c}\text { USCPI } \\
\text { (Consumer Price Index } \\
\text { of the United States) }\end{array}$ \\
\hline Mean & 42.78 & 176.68 \\
\hline Median & 27.43 & 176.05 \\
\hline Maximum & 133.88 & 238.91 \\
\hline Minimum & 11.35 & 108.70 \\
\hline Standard deviation & 30.45 & 39.32 \\
\hline Skewness & 0.97 & -0.0042 \\
\hline Kurtosis & 2.61 & 1.80 \\
\hline
\end{tabular}

Table 1 showed that the price WTI oil price falls between 11.35 and 133.88 USD. Skewness is used to estimate the symmetry of the time series data; while kurtosis is used to measure the peakness of the distribution of variables. The results revealed that there is a positive kurtosis statistic, and the skewness of WTI is approximately equal to 1 , which indicated that there is a right-skewed or the mass of the distribution is stress on the left. A right-skewed distribution usually appears as left-learning curve. However, for the United States Consumer Price Index (USCPI), it is reported as a weak negative skewed variable. 
This is crucial to know the distribution of the time series for a better estimation of the future data point, especially in predicting the financial time series.
The changes in the WTI and USCPI are presented in Fig. 1 and 2, respectively.

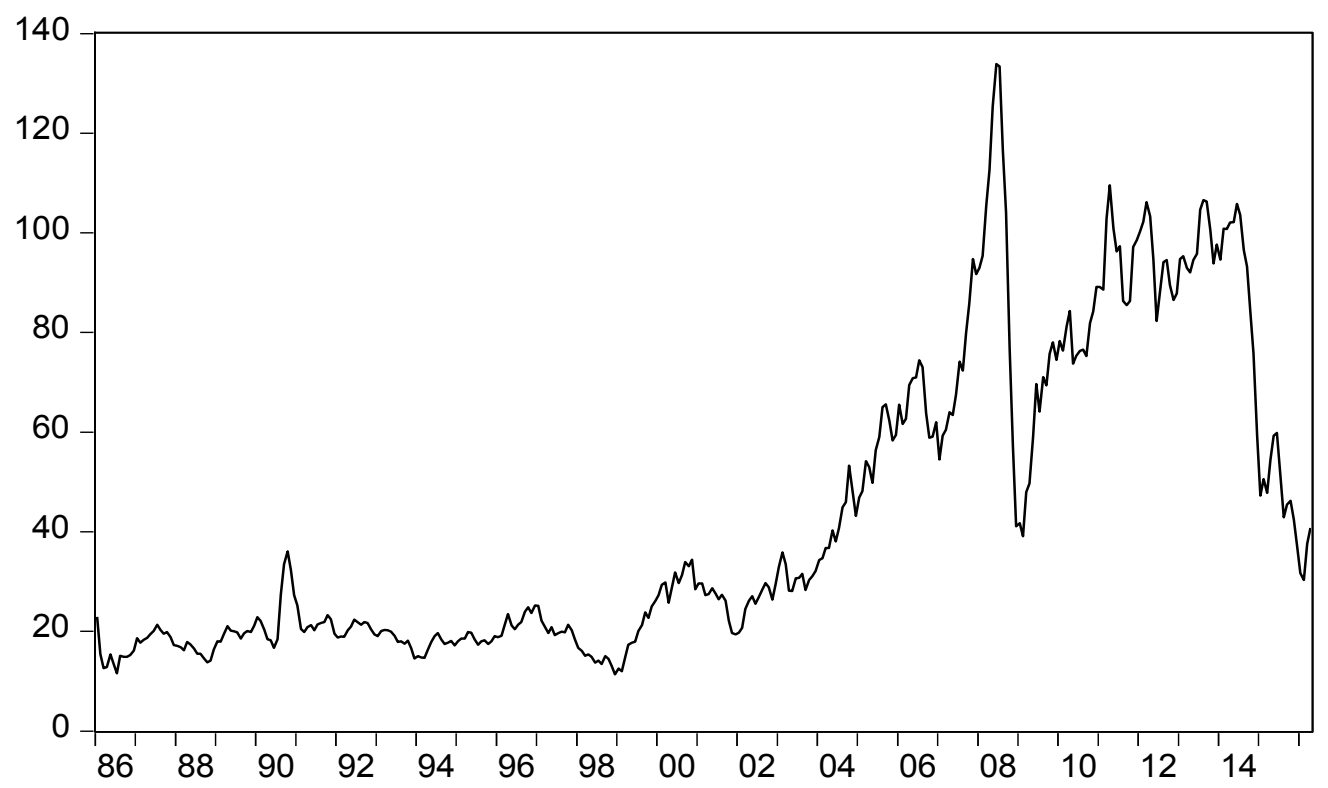

Figure 1. WTI crude oil price (Source: Authors' own research)

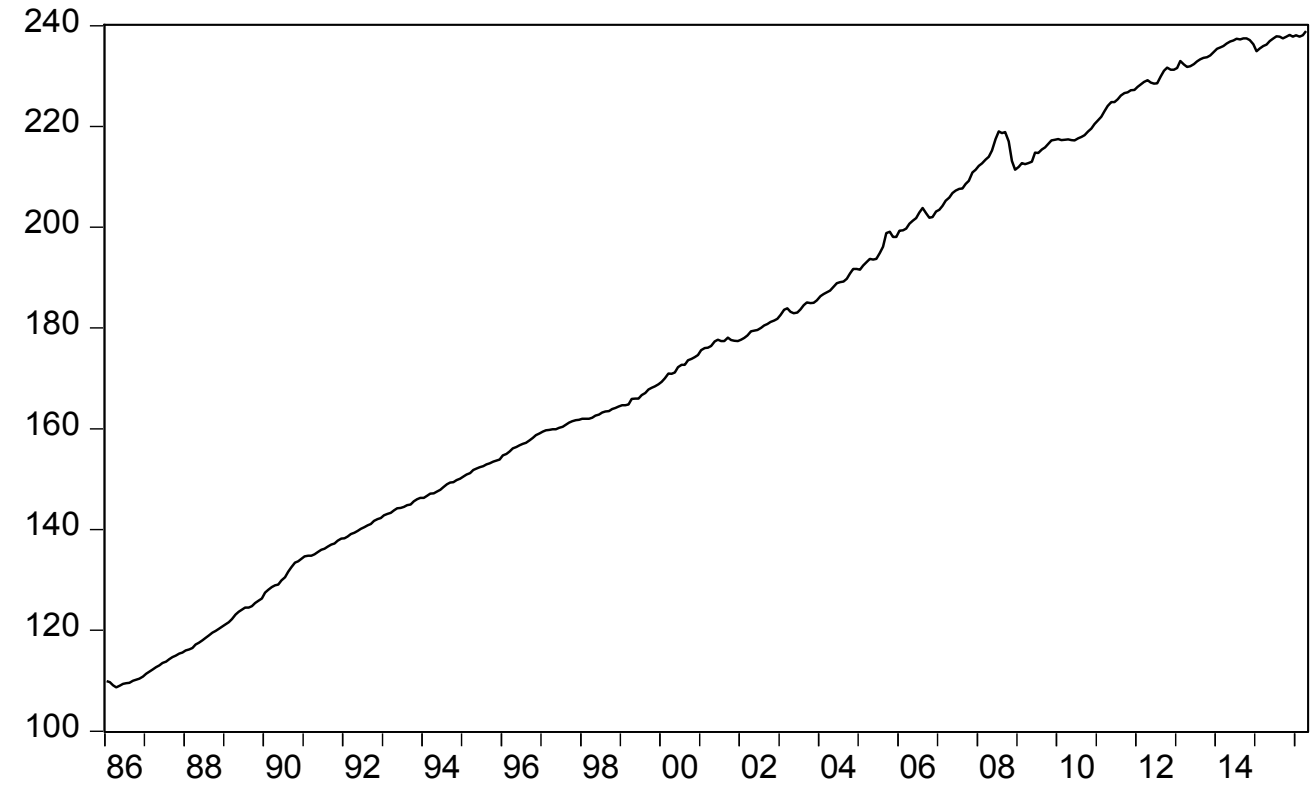

Figure 2. USCPI (Source: Authors' own research)

By referring to Fig. 1, WTI is moving in an irregular way. Breaks might exist because of several timevarying structural changes. Besides, it is reported that USCPI is increased passing the time. Subsequently, multiple structural breaks may occur in the time-varying trend function of many economic time series.
Fig. 1 reported several local maximum and minimum points, including 1991, 2007, 2009, and so on.

The relationship between WTI and USCPI is then measured using least square method, which is reported in Table 2. 
Table 2. Relationship between WTI and USCPI

(Source: Authors' own research)

\begin{tabular}{|l|c|c|c|c|}
\hline \multicolumn{5}{|c|}{ Dependent Variable: USCPI } \\
\hline \multirow{2}{*}{ Variable } & Coefficient & Standard Error & t-Statistic & Probability \\
\hline WTI & 1.07 & 0.04 & 27.85 & 0.00 \\
\hline C & 131.07 & 2.01 & 65.22 & 0.00 \\
\hline R-squared & 0.68 & - & - & - \\
\hline Adjusted R-squared & 0.68 & - & - & - \\
\hline S.E. of regression & 22.21 & - & - & - \\
\hline Prob(F-statistic) & 0.00 & - & - & - \\
\hline
\end{tabular}

In this study, WTI acts as an independent variable, meanwhile USCPI is a dependent variable. To examine the relationship between WTI crude oil price and CPI, 364 observations are used. A positive relationship between WTI and USCPI is reported in Table 2, with a zero p-value. This indicates that there is a significant positive relationship between WTI and USCPI. The equation of the estimated model is given as follows.

Estimation equation:

$$
\mathrm{USCPI}=\mathrm{C}(1) * \mathrm{WTI}+\mathrm{C}(2)
$$

Substituted coefficients:

$$
\mathrm{USCPI}=1.066 * \mathrm{WTI}+131.07
$$

In addition, Akaike information criterion (AIC), Schwarz information criterion (SIC), Hannan-Quinn information criterion (HQ), and log-likelihood tests are used to examine the adequacy of the models.

The formula of AIC, SIC, and HQ information criterion is given as follows:

$$
\begin{aligned}
& \text { AIC: }\left(\frac{2 n}{n-k-1}\right) k-2 \operatorname{In}\left[L_{\max }\right] \\
& \text { SIC: } \operatorname{In}[n] k-2 \operatorname{In}\left[L_{\max }\right] \\
& \text { HQ: } 2 \operatorname{In}(\operatorname{In}[n]) k-2 \operatorname{In}\left[\mathrm{L}_{\max }\right]
\end{aligned}
$$

where $\mathrm{k}$ represents the number of parameters, $\mathrm{n}$ is the number of observations, and $\mathrm{L}$ is the maximized value of the likelihood function under the assumption that the errors are identically independently distributed.

A number of issues arise in the presence of multiple breaks. To estimate the unknown break date, Bai-
Perron (1994) tests are used and the results are summarized in Table 3.

There are three estimated break dates, including August 2008, October 2010, and October 2014, determined using Bai-Perron tests (see Table 3).

The estimate equation based on the findings in Table 3 is given as follows.

Estimation equation:

$\mathrm{WTI}=$

$$
\begin{aligned}
& \text { @BEFORE("2008M08") } \\
& \text { * }(\mathrm{C}(1) * \mathrm{WTI}(-1)+\mathrm{C}(2)) \\
& \text { + @DURING("2008M08 2010M09") } \\
& \text { * (C(3) * WTI(-1) + C(4)) } \\
& \text { +@DURING("2010M10 2014M09") } \\
& \text { * (C(5) *WTI(-1) + C(6)) } \\
& \text { +@AFTER("2014M10") } \\
& \text { * (C(7) * WTI(-1) + C(8)) }
\end{aligned}
$$

Substituted coefficients:

$$
\begin{aligned}
& \mathrm{WTI}= \\
& \text { @BEFORE("2008M08") } \\
& \text { * }(1.038 * \text { WTI(-1) - 0.72) } \\
& \text { + @DURING("2008m08 2010M09") } \\
& \text { * }(0.74 * \text { WTI }(-1)+16.71) \\
& \text { + @DURING("2010M10 2014M9") } \\
& \text { * }(0.68 * \mathrm{WTI}(-1)+31.34) \\
& \text { + @AFTER("2014M10") } \\
& \text { * }(0.76 * \text { WTI }(-1)+9.96)
\end{aligned}
$$

With the restriction trimming $5 \%$ of the sample, the time series is divided into several partitions or regimens: before the first break date (August 2008); during the breaks (August 2008 to September 
2009); during the second break (October 2010 to September 2014), and after the third break (October 2014).
From the adjusted R-squared value of 0.985 for WTI, we can see that past WTI value has a large explanatory power for the current WTI value.

Table 3. Breakpoint Test

(Source: Authors' own research)

\begin{tabular}{|c|c|c|c|c|}
\hline Variable & Coefficient & Std. Error & t-Statistic & Prob. \\
\hline \multicolumn{5}{|c|}{ 1986M02 - 2008M07 - 270 observations } \\
\hline WTI $(-1)$ & 1.04 & 0.01 & 94.08 & 0.00 \\
\hline $\mathrm{C}$ & -0.72 & 0.40 & -1.80 & 0.07 \\
\hline \multicolumn{5}{|c|}{ 2008M08 - 2010M09-26 observations } \\
\hline WTI $(-1)$ & 0.74 & 0.03 & 21.45 & 0.00 \\
\hline $\mathrm{C}$ & 16.71 & 2.61 & 6.40 & 0.00 \\
\hline \multicolumn{5}{|c|}{ 2010M10 - 2014M09 - 48 observations } \\
\hline WTI $(-1)$ & 0.68 & 0.07 & 9.53 & 0.00 \\
\hline $\mathrm{C}$ & 31.34 & 6.78 & 4.62 & 0.00 \\
\hline \multicolumn{5}{|c|}{ 2014M10 - 2016M04 - 19 observations } \\
\hline WTI $(-1)$ & 0.76 & 0.05 & 14.51 & 0.00 \\
\hline $\mathrm{C}$ & 9.96 & 2.87 & 3.47 & 0.00 \\
\hline R-squared & \multicolumn{4}{|l|}{0.99} \\
\hline S.E. of regression & \multicolumn{4}{|l|}{3.72} \\
\hline Probability & \multicolumn{4}{|l|}{0.00} \\
\hline
\end{tabular}

On the basis of the findings obtained, three breaks exist in the series: August 2008, October 2010, and October 2014. Increase in demand from China and India at 2008 leads to a significant rise in oil price, and it reached 145 USD per barrel in July 2008. In June 2008, AFP and Reuters reported that China and India along with the Gulf nations whose retail oil price contributed to $61 \%$ of the increase in global consumption of crude oil and China reported $18 \%$ on retailing petrol and diesel. Several studies such as Hamilton (2009) revealed that sharp rise in oil price contributed to the Global Financial Crisis or also known as Great Recession in 2008. The U.S. financial market started to slide into the financial crisis since the Great Depression of the 1930s in the beginning of the mid-2007 (Thakor, 2015). The cause of the Financial Crisis 2008 can be related with the market instability because of a complex mix of government policy; the development of the real estate market and financial market structure in the U.S. were forces to collapse the financial sector. The second breakpoint date that was detected by the multiple breakpoint test is October 2010. Oil price falls in 2 weeks' time from 88 to 70 USD on May 21, 2010. European Economic Crisis happened when European countries reduced budget deficits. This crisis caused slowdown in American economy, which affects the demand for oil. According to the U.S. Energy Information Administration, 
oil price move back to a former level and reported 90 USD per barrel in December 2010.

This condition caused a sparking fear of second recession if the price rises and reached 100 USD per barrel. Although there are several events that contributed to the structural changes in oil price, the third breakpoint date was found at October 2014. In 2014, the crude oil price is in an instable condition. This is because cool weather in the United States resulted in high heating oil demand on February 2014; lower oil supplies in Oklahoma pushed the price to reach 102.12 USD for benchmark WTI crude and 108.29 USD for Brent; low demand with high supply from North American production contributed to downward on benchmark crude. In October 2014, WTI crude oil falls below 80 USD, the lowest price value since November 2010 because of the robust global production of crude oil exceeded the demand in the fourth quarter of 2014.

Next, we are interested to know the effect of break dates of WTI on the changes in CPI. The CPI data provided by the U.S. Department of Energy and Bureau of Labor Statistics are available on a monthly basis. To have a better overview of the CPI data, a line graph is sketched and presented in Fig. 3.

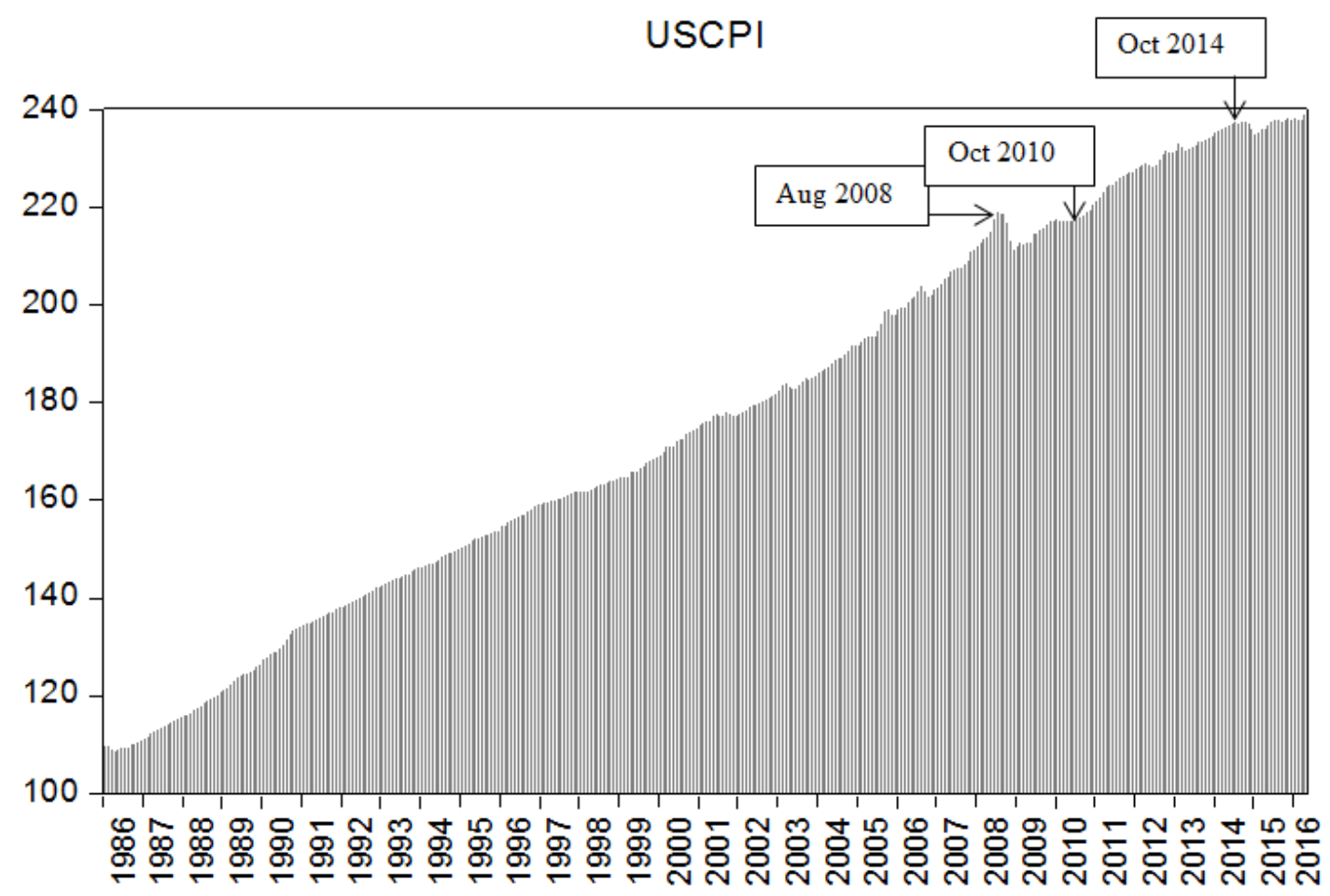

Figure 3. Changes in the USCPI (Source: Authors' own research)

Fig. 3 showed the line graph to depict the changes in the CPI with respect to time. From Figure 3, three estimated break dates, August 2008, October 2010, and October 2014, are found for the USCPI. Depreciation is reported in August 2008 after the local maximum point at July 2008. The next break date, October 2010 has a rising point of 0.7 indices compared to the previous month; and October 2014 is the turning point from a stable condition to a depreciation condition in CPI.

\section{Conclusion}

The effects of oil price on inflation vary in different countries at different periods whereby mixed evidenced are found showing the direct effect of oil prices, declining pass through effect and even the absence of the impact of oil price on inflation. This can be proved by Arinze (2011) that there is a positive relationship between oil price and inflation whereby the inflation rate increases whenever the petrol price increase and such effects is shown 
in the Consumer Price Index. Similarly, Kim and Willet (2000) analyzed the effects of the oil supply shocks in order to look into the view of the oftendocumented negative relationship between inflation and economic growth using the OECD countries and less-developed countries. They studied the structural breakpoints using the Chow test and CUSUM test. The result showed that oil price shock has an impact on the inflation of the OECD countries where the coefficient of inflation becomes significantly negative during post-shock period. In conclusion, the breakpoints date on crude oil price estimated using the Bai-Perron test is supported by the economic events, including Asian Financial crisis, European Economic Crisis, and Financial Crisis 2008. Moreover, On the basis of the findings and literature on economic events in the past, oil price fluctuation is proved to have a relationship with country's CPI.

\section{Acknowledgments}

The authors are greatly acknowledging the financial support provided by University of Malaya Research Fund Assistance (BKP) under project number BK010-2017.

\section{References}

[1] Andrews, D.W.K., 1993. Tests for Parameter Instability and Structural Changes with Unknown Change Point. Econometrica, 61, pp.821856.

[2] Andrew, W.K., Ploberger, W., 1996. Optimal Change Point Tests for Normal Linear Regression. Journal of Econometrics, 70, pp.9-38.

[3] Arinze, P.E., 2011. The Impact of Oil Price on the Nigerian Economy. Jorind, 9, pp.211-215.

[4] Bai, J., Perron, P., 2003. Critical Values for Multiple Structural Change Tests. Econometrics Journal, 6, pp.72-78.

[5] Behrens, J.T., Yu, C.H., 2003. Exploratory Data Analysis. New Jersey: John Wiley \& Sons, Inc.

[6] Carruth, A.A., Hooker, M.A. and Oswald, A.J., 1998. Unemployment Equilibria and Input Prices: Theory and Evidence from the United Sta- tes. Review of Economics and Statistics, 80, pp.621-628.

[7] Chaudhuri, K., Daniel, B.C., 1998. Long-run Equilibrium Real Exchange Rates and Oil Prices. Economics Letters, 58, pp.231-238.

[8] Chow, G., 1960. Tests of Equality between Sets of Coefficients in Two Linear Regressions. Econometrica, 28, pp.591-605.

[9] Cong, R.G., Wei, Y.M., Jiao, J.L. and Fan, Y., 2008. Relationships between Oil Price Shocks and Stock Market: An Empirical Analysis from China. Energy Policy, 36, pp.3544-3553.

[10] Cunado, J., De Gracia, F.P., 2005. Oil Prices, Economic Activity and Inflation: Evidence for some Asian Countries. The Quarterly Review of Economics and Finance, 45, pp.65-83.

[11] Davis, S.J., Haltiwanger, J., 1999. Gross Job Flows. Handbook of Labor Economics, 3, pp.2711-2805.

[12] Hamilton, J.D., Lin, G., 1996. Stock Market Volatility and the Business Cycles. Journal of Applied Econometrics, 11, pp.411-434.

[13] Hamilton, J.D., 2009. Causes and Consequences of the Oil Shock of 2007-08. National Bureau of Economic Research. [online] Available through: <http://www.nber.org/papers/w15002. pdf $>$ [Accessed on 27 December 2018].

[14] Hooker, M.A., 2002. Are Oil Shocks Inflationary? Asymmetric and Nonlinear Specifications Versus Changes in Regime. Journal of Money, Credit, and Banking, 34, pp.540-561.

[15] Ibrahim, M.H., Chancharoenchai, K., 2014. How Inflationary are Oil Price Hikes? A Disaggregated Look at Thailand Using Symmetric and Asymmetric Cointegration Models. Journal of the Asia Pacific Economy, 19, pp.409-422.

[16] Mallik, G., Chowdhury, A., 2001. Inflation and Economic Growth: Evidence from Four South Asian Countries. Asia-Pacific Development Journal, 8, pp.123-135.

[17] Phoong, S.W., Phoong, S.Y. and Sulaiman, A., 2018. Asymmetric Effects of the Effect of Oil Price on Stock Markets in Four Asian Countries: Markov Switching Analysis. The Journal of Social Sciences Research, 6(S), pp.423-428.

[18] Phoong, S.W., Phoong, S.Y., 2017. Modelling the Economic Cycle between GDP and Govern- 
ment Spending on Technological Innovation. Pertanika Journal of Social Sciences and Humanities, 25(S), pp.45-52.

[19] Quandt, R., 1960. Test of the Hypothesis that a Linear Regression System Obeys two Separate Regime. Journal of the American Statistical Association, 55, pp.324-330.

[20] Sauter, R., Awebuch, S., 2003. Oil Price Volatility and Economic Activity: A Survey and Literature Review. Paris: IEA Research Paper.
[21] Thakor, M., 2015. How Falling Oil Prices Make a Black-Swan Event More Likely. The Wall Street Journal. [online] Available through: $<$ https://blogs.wsj.com/experts/2015/01/08/howfalling-oil-prices-makes-a-black-swan-event-mo re-likely/> [Accessed on 2 January 2019].

[22] Yuan, G., Li, X., 2010. A Modified Consumer Price Index. Modern Economy, 1, pp.112-117. 